\title{
Foramen Magnum Meningioma: Far Lateral Approach
}

\author{
Ciro Vasquez $^{1}$ Alexander Yang $^{1} \quad$ A. Samy Youssef ${ }^{1}$ \\ ${ }^{1}$ Department of Neurosurgery, University of Colorado, Aurora, \\ Colorado, United States \\ J Neurol Surg B 2019;80(suppl S4):S363-S364.

\begin{abstract}
Address for correspondence A. Samy Youssef, MD PhD, Department of Neurosurgery, University of Colorado, Mail Stop C307, 12631 East 17th Avenue, Aurora, CO 80045, United States (e-mail: samy.youssef@ucdenver.edu).
\end{abstract}

\begin{abstract}
We present a case of a foramen magnum meningioma in a 42-year-old female who presented with headaches for 2 years, associated with decreased sensation and overall feeling of "heaviness" of the right arm. The tumor posed significant mass effect on the brainstem, and given the location of the tumor in the anterolateral region of the foramen magnum, a right far lateral approach was chosen. The approach incorporates the interfascial dissection technique to safely expose and preserve the vertebral artery in the suboccipital triangle. After drilling the posteromedial portion of the occipital condyle and opening the dura, the tumor can be entirely exposed with minimal retraction on the cerebellum. The working space offered by the far lateral approach allows careful dissection at the lateral craniocervical junction, and preservation of the

Keywords

- vertebral artery

- occipital condyle

- foramen magnum meningioma

- interfascial technique V4 segment of the vertebral artery and the lower cranial nerves. Simpson's grade- 2 resection was achieved with coagulation of the dural base around the vertebral artery. The postoperative course was unremarkable for any neurological deficits. At the 2-year follow-up, imaging identified no recurrence of tumor and the patient remains asymptomatic.

The link to the video can be found at: https://youtu.be/IMN107v05B0.
\end{abstract}

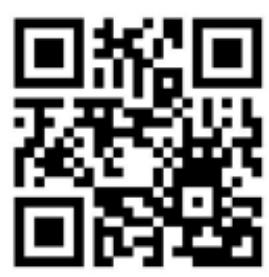

received

February 17, 2019

accepted after revision

July 8, 2019

published online

October 15, 2019

www.thieme.com/skullbasevideos

www.thieme.com/jnlsbvideos

DOI https://doi.org/

10.1055/s-0039-1695701. ISSN 2193-6331.
๑) 2019 Georg Thieme Verlag KG
Stuttgart · New York

License terms

(c) (i) $\ominus$ (\$) 


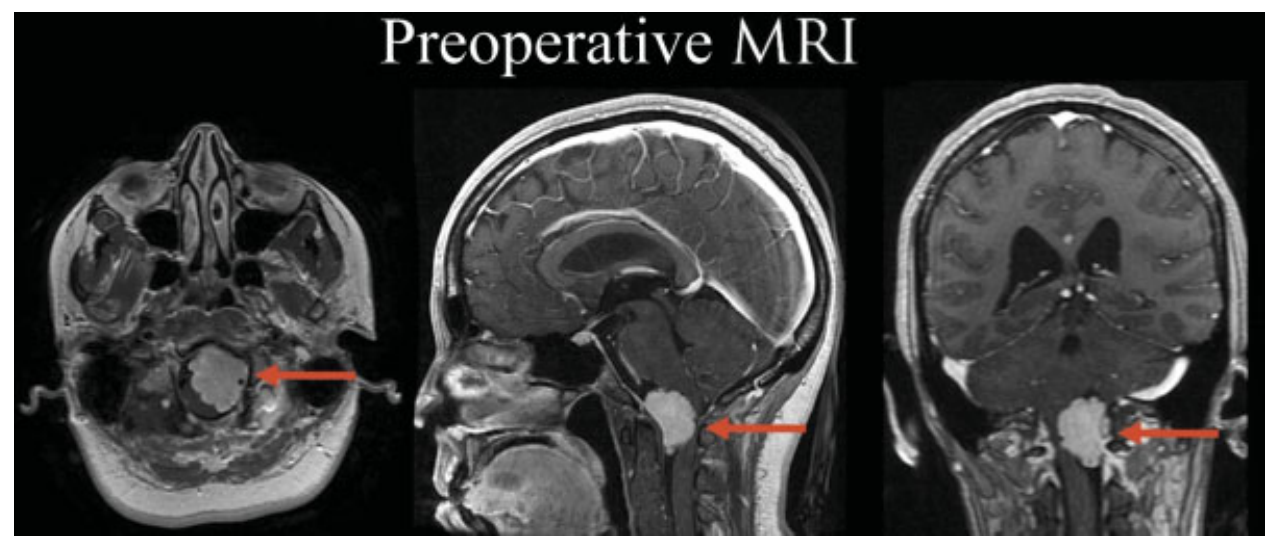

Fig. 1 Preoperative MRI demonstrating vertebral artery V4 segment encased in tumor. MRI, magnetic resonance imaging.

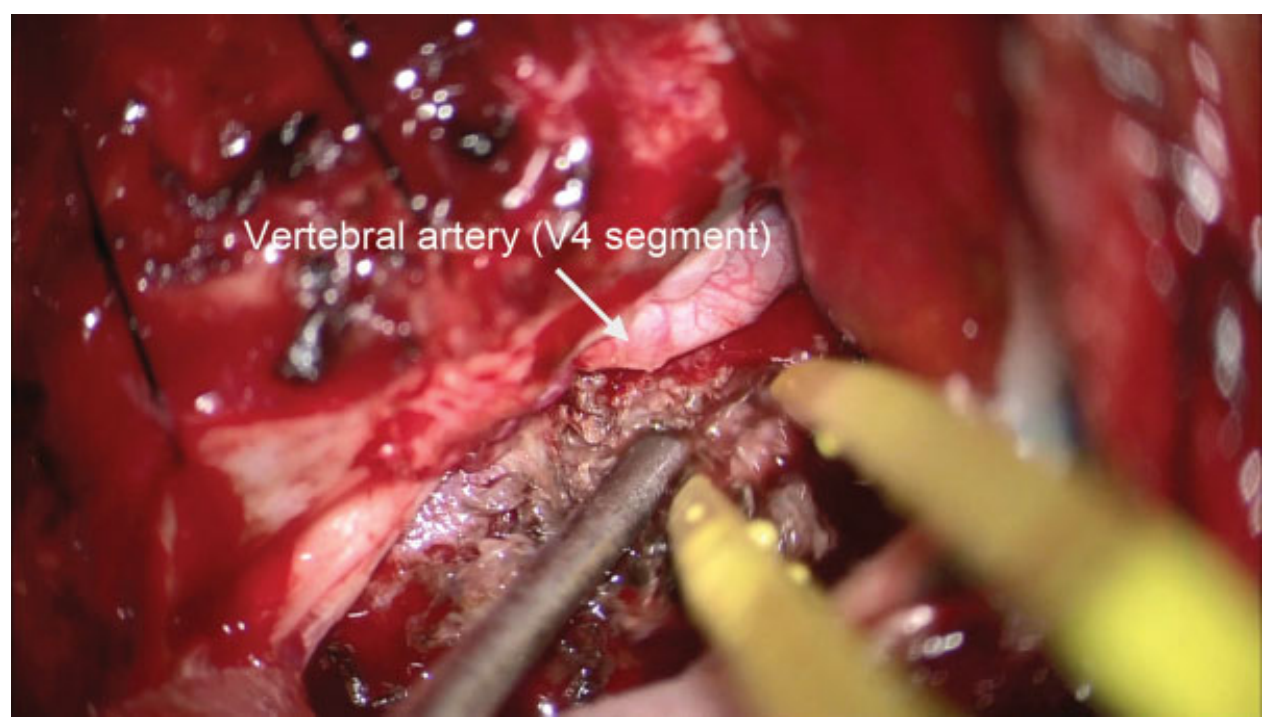

Fig. 2 Intraoperative identification and isolation of the vertebral artery V4 segment.

\section{Publication Comments}

The authors present a trans condylar far lateral approach for the removal of a foramen magnum meningioma which is encasing the left vertebral artery. I would like to commend the authors for a great postoperative result which has shown in the follow up no recurrence. The thorough analysis of the transcondylar approach vs retro condylar is educational for the formation of skull base surgeons to understand the advantages of the approach.

Diego Mendez Rosito, MD

CMN 20 de Noviembre Mexico City, Mexico

Conflict of Interest

None declared. 